\title{
Managing Multichannel Strategies In The Service Sector: The Example Of The French Insurance Industry
}

Ilaria Dalla Pozza, IPAG Business School, France

Lionel Texier, Managing Director Risk \& Analysis, France

\begin{abstract}
The goal of this paper is to investigate the implementation of multichannel strategies in the service sector and to understand objectives, difficulties faced by companies, synergies and competitive effects among channels, and future areas of investment. The research questions used in-depth interviews with a sample of insurance directors responsible for the multichannel strategy of the major French insurance players.
\end{abstract}

Keywords: Multichannel Strategy; Insurance Industry

\section{INTRODUCTION}

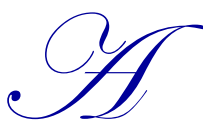

ccording to Neslin et al. (2006), multichannel management refers to the integrated deployment and coordination of channels firms use to connect and exchange with customers, with the end goal of improving customer acquisition, development, and retention. For companies, developing a multichannel strategy has become a key commercial lever as well as a necessary business development tool (Neslin et al., 2006). Customers have a host of channels at their disposal whereby they can purchase a product (distribution channels) and communicate with companies (information channels) (Kumar \& Venkatesan, 2005; Dholakia et al., 2010; Verhoef et al., 2010). These include 'bricks-and-mortar' retail stores, sales representatives, mail-order catalogues, e-mail, call centers, websites and, more recently, social media such as Twitter and Facebook (Dalla Pozza, 2014).

However, the existence of multiple channels also poses a challenge for the firms that have to integrate and manage them. Strategic research on multichannel management is rare in the academic literature (Neslin et al., 2006; Klaus \& Nguyen, 2013). Most studies in the multichannel field have focused on customers' multichannel behavior when confronted with two channels, even though multichannel behavior is more complex than this (Heitz-Spahn, 2013; Dalla Pozza, 2014). Multichannel customer behavior needs to take the whole of the purchasing process into consideration (Dalla Pozza, 2014; Gensler et al., 2012). In addition, the majority of studies in the multichannel literature have addressed the issue of tangible products, while research on the service sector is relatively scarce (Klaus \& Nguyen, 2013).

Accordingly, this research seeks to understand how a multichannel strategy can be implemented by companies in a service sector, answering the following research questions:

1. What are the objectives of a multichannel strategy?

2. What challenges do companies face?

3. What synergies and conflicts exist between the different channels?

From a managerial perspective, the present study contributes to furthering our understanding of the multichannel field, providing guidelines and action models for businesses in the service sector. 


\section{METHODOLOGY AND SAMPLE}

We selected the French insurance sector to explore the implementation of a multichannel strategy in a complex service context. There were several reasons behind our choice:

- $\quad$ The insurance industry plays a major role in economic growth and development.

- $\quad$ Insurance products continue to be viewed as complex services by consumers.

- $\quad$ The insurance industry comprises a vast number and range of distribution and information channels. For instance, in distribution (sales), we find either direct sales (through telemarketing or via the Internet) or agency-based distribution. In addition, agencies may be owned by insurance companies themselves or by independent insurance agents. The service may also be provided by insurance brokers. As regards communication channels, insurers employ numerous different channels to interact with consumers and build customer relations, such as call centers, Internet, social media and agencies, chats, and e-mail.

In order to answer our research questions, we designed a questionnaire and then conducted face-to-face or phone interviews with multichannel directors, heads of marketing or development, and managing directors responsible for the implementation of multichannel strategies for the leading insurance firms in France. The interviews are typically used in exploratory research (Miles \& Huberman, 1994).

The respondents were selected according to the following criteria:

- $\quad$ Their company's turnover. Specialized magazines in the French insurance industry report annually the rankings of insurance companies based on their turnover. Rankings can report the total turnover of the company or the turnover for a specific market (such as home insurance, motor insurance, health insurance, etc...). Our sample is composed by companies listed in the top 10 of these rankings.

- $\quad$ Their availability to take part in the multichannel study.

- $\quad$ The corporate multichannel experience of the respondent. The respondent was required to have a certain level of seniority in his position (at least one year).

The interview and data collection phases of our survey took place between May and November 2013. All the interviews were recorded in audio format and then transcribed into text. We gathered 16 case studies, analysing 11 groups in the insurance industry. Several case studies were sometimes developed for the same insurance group when the latter is organized into distinct structures in order to sell different products under different brand names, thus targeting several market segments. The saturation criteria was reached (Strauss \& Corbin, 1998). According to the customer distribution channels, the sample can be represented as follow:

- $\quad$ Bank insurances: 3

- $\quad$ Direct sales: 3 property \& casualty and 3 life insurance

- $\quad$ Affinity businesses: 1

- $\quad$ Insurance through a proprietary network of agencies: 3

- $\quad$ Insurance through intermediaries (insurance brokers or agents): 3

To answer our research questions, we performed a content analysis and compared the different interviews (Glaser \& Strauss, 1967).

\section{OBJECTIVES OF A MULTICHANNEL STRATEGY}

Those interviewed recognized the growing importance of having a multichannel strategy in place, which has become an essential lever in corporate strategy, and a driver of growth and business development.

Today's customers demand more choice in the way they interact with companies and have changed the way they search for information as well as their consumption behavior. This has forced companies to adapt, and to develop several different channels to interact and exchange with customers. Thus, a multichannel strategy answers the customer need of having several channels available. Establishing new distribution and/or communication channels not only provides the means to satisfy customers, but also expands the market by attracting new ones. 
Regarding the goals of their multichannel strategy, the companies indicated that:

- $\quad$ A multichannel strategy is introduced to satisfy customers' needs and expectations.

- When the agency's role is deemed to be central, multiple channels are used by the agent as tools to strengthen customer relations; the agent is then able to promote new channels (e.g., website, Smartphone application...) for the customers.

- $\quad$ Another goal is cost reduction: digital channels help reduce costs (e.g.: a life and health insurance sales campaign aimed at the general public by an insurance company with a low communications budget led to the launch of a 100\% digital communications campaign comprising a website, a Twitter account, a Facebook page, blogs, and the involvement of Internet opinion leaders).

\section{THE CHALLENGES INVOLVED IN IMPLEMENTING A MULTI-CHANNEL STRATEGY} mentioned:

Among the main difficulties faced in the implementation of a multichannel strategy, the companies

- $\quad$ Budgetary constraints.

- $\quad$ The effort required to integrate the channels rather than simply align them alongside one another.

- The technological challenge of ensuring effective communication between the different channels, especially if each subsidiary develops its own IT infrastructure in isolation.

- $\quad$ The necessity of building customer trust through the multiple channels, as the complexity of the service provided increases.

- $\quad$ Change management (both internally and with partners) in the case of companies with a large network of agents (or brokers) was often mentioned by respondents.

Regarding this last point, companies that rely on a traditional distribution network largely made up of intermediaries (agents and/or brokers) face a major challenge: the changing role of the agent in an age of digitalization and multiple channels.

Among the sources of conflict to watch out for is the 'fear' that traditional distribution (the agencies) will be 'cannibalized' by direct distribution. Insurance companies thus stress the importance of change management and the need for an appropriate commission system. Below is an extract from one of the interviews:

....The challenge is to bring the digital into the everyday world of the salespersons, to integrate and understand all the channels. Salespersons should be able to fully grasp the issues at stakes for the channels overall, and be able to use them effectively while understanding that they (the salespersons) are the source of business. The human factor is fundamental. There's the technological factor, but there's also the human factor. The tool is nothing without the worker. Times are changing and we are entering a digital age.'

\section{SYNERGIES AND CONFLICTS BETWEEN THE CHANNELS}

The interviewed directors recognize channels must work in synergy rather than compete with one another. The importance of a smooth customer path and the need to create transitions and links among channels were often noted. We also noted the cross-channel issue, in other words, the importance of making a variety of different channels available to the customer and creating gateways between them. This facilitates the buying process for customers, helps instil trust and, ultimately, boosts customer satisfaction and loyalty. In the field of complex services for instance, consumers are still wary of online subscriptions due to lack of trust. As the complexity of the service increases, customers prefer face-to-face or telephone interactions. By exploiting the synergies between the channels, insurers have introduced a telephone support service to help people complete the online subscription process.

The synergies between the internet and telephone channels were also mentioned by the leading players in direct insurance in France. They all agreed that the lion's share of sales is generated over the phone despite the option to complete a subscription online. Percentages for subscriptions completed over the phone range between 75 and $90 \%$, the rest being done online. This is the case for both property \& casualty products and life and health 
insurance. Regarding the main conflicts observed, we noted the internal resistance of traditional distribution networks (insurance agents) to the implementation of a multichannel strategy.

\section{INVESTMENT STRATEGIES IN THE DIFFERENT CHANNELS}

The directors interviewed plan to invest in distribution and communication channels in the near future. By and large, the implementation of multiple channels is developed to a greater degree in the pre-purchase and purchase phases than in the post-purchase phase, although companies intend to develop all three of these areas in the coming years. The current level of development for communication channels both in the pre-purchase phase (customer information, quotes, checking guarantees) and in the post-purchase phase (claims management, customer relations) on a scale of $0-3$ (where 0 is non existent and 3 is highly developed), as well as the future level of investment over the next three years for each channel (on a scale of $0-3$, where 0 is not a priority and 3 is high priority) was investigated.

Table 1: Communication Channels (Scale 0 - 3)

\begin{tabular}{|l|c|c|c|c|}
\cline { 2 - 5 } \multicolumn{1}{c|}{} & \multicolumn{2}{c|}{ Pre - Purchase } & \multicolumn{2}{c|}{ Post - Purchase } \\
\cline { 2 - 5 } Company's website & Today & Future & Today & Future \\
\cline { 2 - 5 } Call center & 2.45 & 2.91 & 1.80 & 2.80 \\
E-mail & 2.18 & 2.40 & 2.40 & 2.11 \\
Agency & 1.80 & 2.44 & 1.89 & 2.25 \\
Aggregator & 1.63 & 1.86 & 1.22 & 1.63 \\
Mobile & 1.44 & 2.11 & 0.00 & 0.00 \\
Broker & 1.27 & 2.56 & 1.13 & 2.78 \\
Other social media & 0.89 & 0.67 & 0.00 & 0.00 \\
Chat & 0.86 & 1.83 & 0.50 & 1.60 \\
Facebook & 0.82 & 1.60 & 0.43 & 1.75 \\
Twitter & 0.70 & 1.78 & 0.80 & 1.75 \\
& 0.30 & 1.78 & 0.70 & 1.75 \\
\hline
\end{tabular}

Specifically, insurance companies will continue to invest in traditional communication channels such as call centers or agencies in both the pre-purchase and post-purchase phases (Table 1), even though these more traditional channels have already reached a satisfactory level of development. In these areas, less developed channels that are expected to take center stage in the future are: the mobile phone, chat, e-mail, and social media such as Twitter and Facebook. The pre-purchase phase will also be further strengthened by aggregators to attract new customers and gain visibility on the web. As for the post-purchase phase, insurers plan to upgrade their websites in order to improve customer service, customer accounts management, and claim management.

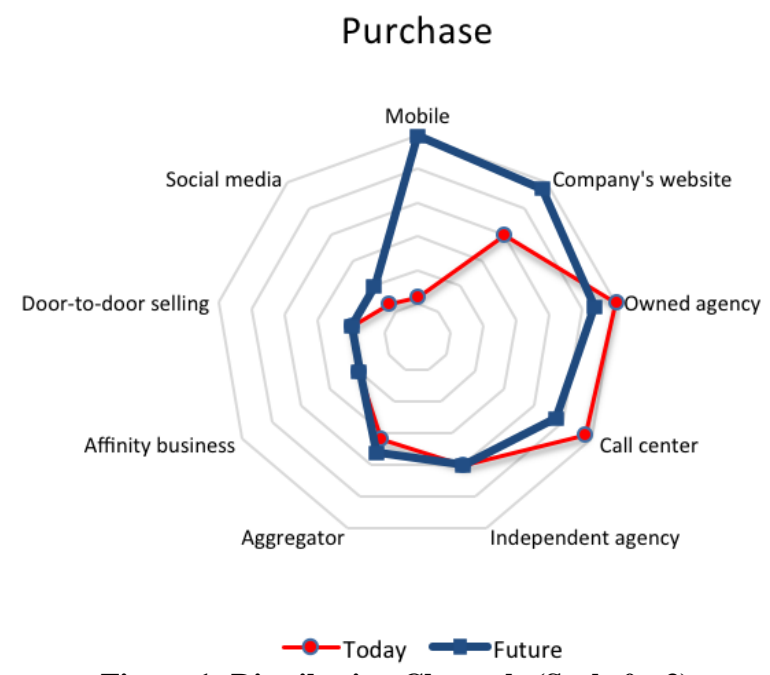

Figure 1: Distribution Channels (Scale 0 - 3) 
Similarly, regarding future investments for distribution channels, website enhancement, and the mobile phone remain the priority for firms (Figure 1). At the same time, even if they are already developed, traditional channels such as agencies and call centers will also be considered for further investment.

\section{CONCLUSION}

The implementation of a multichannel strategy in the service industry involves a level of complexity and numerous challenges for companies, especially given the intangible nature of services. This study analyzed the goals, the difficulties, the synergies and complementarities between the different communication and distribution channels when implementing a multichannel strategy in the French insurance industry. While all those interviewed agreed that multiple channels are necessary to satisfy customers' needs and expectations, especially for companies characterized by a traditional distribution network (agencies), managing the transition and ensuring that agents embrace the multichannel strategy remains a significant challenge. In addition, as the complexity of the service increases, special care should be devoted to the development of customer trust among the different channels.

\section{AUTHOR INFORMATION}

Ilaria Dalla Pozza, IPAG Business School, Marketing Department, Paris, France. E-mail: ilaria.dallapozza@ipag.fr (Corresponding author)

Lionel Texier, Managing Director Risk \& Analysis, Paris, France

\section{REFERENCES}

1. Dalla Pozza, I. (2014). Multichannel management gets social. European Journal of Marketing, 48 (5/6).

2. Dholakia, U., Kahn, B. E., Reeves, R., Rindfleisch, A., Stewart, D., \& Taylor, E. (2010). Consumer behavior in a multichannel, multimedia retailing environment. Journal of Interactive Marketing, 24(2), 8695.

3. Gensler, S., Verhoef, P., \& Böhm, M. (2012). Understanding consumers' multichannel choices across the different stages of the buying process. Marketing Letters, 23(4), 987-1003.

4. Glaser, B., \& Strauss, A. (1967). The discovery of grounded theory: Strategies for qualitative research. New York: Aldine.

5. Heitz-Spahn, S. (2013). Cross-channel free-riding consumer behavior in a multichannel environment: An investigation of shopping motives, sociodemographics and product categories. Journal of Retailing and Consumer Services, 20(6), 570-57.

6. Klaus, P., \& Nguyen, B. (2013). Exploring the role of the online customer experience in firms' multichannel strategy. Journal of Strategic Marketing, 21(5), 429-442.

7. Kumar V., \& Venkatesan, R. (2005). Who are multichannel shoppers and how do they perform? Correlates of multichannel shopping behaviour. Journal of Interactive Marketing, 19, 44-61.

8. Miles, M., \& Huberman, M. (1994). Qualitative data Analysis. London: Sage Publications.

9. $\quad$ Neslin, S. A., Grewal, D., Leghorn, R., Shankar, V., Teerling, M., Thomas, J., \& Verhoef, P. (2006). Challenges and opportunities in multichannel customer management. Journal of Service Research, 9, 95113.

10. Strauss, A., \& Corbin, J. (1998). Basics of qualitative research: Techniques and procedures for developing grounded theory. Thousands Oaks, CA: Sage Publications.

11. Verhoef, P. C., Venkatesan, R., McAlister, L., Malthouse, E. C., Krafft, M., \& Ganesan, S. (2010). CRM in datarich multichannel retailing environments: a review and future research directions. Journal of Interactive Marketing, 24(2), 121-137. 
NOTES 